\title{
ADOÇÃO POR HOMOSSEXUAIS NA \\ GRANDE VITÓRIA-ES: UMA PERSPECTIVA INTERDISCIPLINAR
}

\author{
Natane Franciella de Oliveira ${ }^{1}$ \\ Janaina Gomes Garcia Moraes ${ }^{2}$ \\ Sandro José da Silva ${ }^{3}$
}

\section{ADOPTION OF CHILDREN BY HOMOSEXUALS IN VITORIA METROPOLITAN AREA-ES: AN INTERDISCIPLINARY PERSPECTIVE}

RESUMO: Este artigo analisa adoções homoafetivas ocorridas na Grande Vitória - ES. O objetivo da pesquisa consiste em descrever como os homossexuais da região realizam sua parentalidade em face das possibilidades e constrições do Direito e da realidade. Para tanto, foram utilizados os métodos da etnografia e da história de vida junto a pais, filhos e pretendentes à adoção, entre outubro de 2015 e julho de 2016 outubro de 2015 e julho de 2016. Seus relatos demonstraram que a ausência de previsão legal expressa quanto à adoção homoafetiva, a aquiescência à heteronormatividade, a postura dos agentes públicos e as experiências de vida influenciam na maneira como adotam e exercem a parentalidade.

Palavras-chave: Adoção. Homossexual. Etnografia.
ABSTRACT: This article analyzes adoptions by homosexuals that took place in Vitória Metropolitan area - ES. The objective of the research is to describe how homosexuals in the region perform their parenting in the face of the possibilities and constraints of law and reality. To do so, the methods of ethnography and life history were employed among parents, children and prospective adoptive parents between October 2015 and July 2016. Their stories showed that the absence of legal provisions explicitly allowing their adoption, the acquiescence to heteronormativity, the posture of public agents and life experiences influence the way they adopt and exercise their parenthood.

Keywords: Adoption. Homossexual. Ethnography.

\footnotetext{
${ }^{1}$ Universidade Federal do Espírito Santo. Graduada em Direito pela PUC/MG. Mestre em Direto Processual na Universidade Federal do Espírito Santo.

${ }^{2}$ Graduada em direito pela Universidade Federal Fluminense. Pos graduada em direito constitucional aplicado pela faculdade de direito Damásio de Jesus. Mestranda em direto na UFES.

${ }^{3}$ Doutor em Antropologia pela Universidade Federal Fluminense, Professor na Universidade Federal do Espírito Santo.
} 


\section{INTRODUÇÃO}

Desde que o Supremo Tribunal Federal (STF), em 2011, reconheceu as uniões entre pessoas do mesmo sexo como análogas às uniões estáveis heterossexuais, as discussões sobre as famílias homoafetivas têm se intensificado no espaço público. De um lado, há os "defensores da família", que, como o vereador de Vitória Davi Esmael, rejeitam que casais homoafetivos possam receber esse título: "ainda que seja legal, atinge a moral e a essência do modelo de família em que o casamento é uma instituição cristã entre homem e mulher, não sendo reconhecida qualquer composição diferente disso" ${ }^{4}$. De outro, há os "defensores das famílias", que entendem que não existe uma só configuração possível para os grupos que assim se denominam atualmente, como a jurista Maria Berenice Dias (2014).

Nesse embate, a adoção entra como um ponto central de controvérsias. Uma vez que conceber um filho depende da diferenciação sexual, a falta dessa diversidade no exercício da parentalidade serve aos opositores como argumento para que a adoção homoafetiva seja contestada, visto que não pode mimetizar a biologia. Exemplo dessa espécie de raciocínio é encontrada no segundo parecer exarado na Câmara dos Deputados acerca do projeto de lei conhecido como Estatuto da Família. Quando o deputado Diego Garcia, autor desse parecer, afirma que a adoção, legal e constitucionalmente prevista, prefere o casamento e a união estável heterossexual, e somente quando não houver essa possibilidade, a adoção monoparental (ALBUQUERQUE DE ABREU, 2016), ele reforça a ideia de que a adoção procura imitar a biologia. Há, nesses discursos, uma naturalização da construção social, dependente de uma conjuntura econômica e social específica (CANEVACCI, 1981; DONELOT, 1986), que é a família. Nas palavras de Cláudia Fonseca (1995, p. 20):

A palavra 'família' se restringe no nosso imaginário à família conjugal, uma família que implica a co-residência de um casal e seus filhos - sendo a casa o lugar das mulheres e crianças; e o espaço público da rua, o domínio por excelência dos homens. Imaginamos que há algo natural neste modelo. Dotamo-nos de um valor

\footnotetext{
${ }^{4}$ Fala do vereador Davi Esmael (Vitória - ES) sobre a realização de casamento coletivo homoafetivo, conforme noticiado em http://www.gazetaonline.com.br/noticias/cidades/2016/05/1-casamento-legal-homoafetivo-coletivode-vitoria-acontece-neste-sabado-1013945389.html. Acesso 25.ago.2017.
} 
moral universal. Esquecemos que esse modelo emergiu no bojo de um contexto específico, por volta do século XVIII, que teria sido impossível ele se consolidar sem certos elementos históricos - a centralização do Estado, por exemplo, e a individualização de salários.

Mas, há também aqueles que, reconhecendo sua essência histórica, advogam que a família não está nem nunca esteve condicionada aos limites biológicos. Desse modo, não haveria essencialmente impedimentos para o exercício da parentalidade por parte dos homossexuais. Trata-se da visão dominante no Superior Tribunal de Justiça, ilustrado pelo julgado abaixo:

VI. Estudos feitos no âmbito da Psicologia afirmam que pesquisas "(...) têm demonstrado que os filhos de pais ou mães homossexuais não apresentam comprometimento e problemas em seu desenvolvimento psicossocial quando comparados com filhos de pais e mães heterossexuais. O ambiente familiar sustentado pelas famílias homo e heterossexuais para o bom desenvolvimento psicossocial das crianças parece ser o mesmo" [...] . (REsp 1.281.093-SP)

Como os diversos trabalhos sobre a temática demonstram ${ }^{5}$, a academia não passou alheia ao debate. As pesquisas sobre o tema explicitam as expectativas, os discursos, as motivações, as dificuldades e os facilitadores (jurídicos ou não) quando da adoção por homossexuais (e.g., COITINO FILHO, 2014, 2015; UZIEL, 2007, 2012; RINALDI, 2013, 2015; COITINO FILHO, RINALDI, 2015; BARANOSKI, 2016; FARIAS, 2012; FARIAS, MAIA, 2012). Neste artigo ${ }^{6}$, tendo como pano de fundo a ambivalência da sociedade e do Direito brasileiro quanto ao tema, procuramos responder à seguinte pergunta: que fatores sociais e jurídicos influenciam a adoção por homossexuais da Grande Vitória - ES? A resposta a essa pergunta objetiva descrever os caminhos pelos quais os homossexuais da Grande Vitória - ES buscam e exercem a adoção, bem como explicar as dinâmicas dessas adoções em face do Direito. A adoção, na pesquisa, é entendida sob três perspectivas: aquela regulamentada pela legislação; a denominada adoção à brasileira; e aquela em que vínculos se formam sem que outros se percam, chamada de circulação de crianças (FONSECA, 1995).

\footnotetext{
${ }^{5}$ Pesquisa no Banco de Teses e Dissertações da CAPES com os termos de busca "adoção" e "homossexuais", ajustado o filtro de área para Direito e Antropologia, apresentou 1401 resultados em 27/08/2017.

${ }^{6}$ Este artigo deriva da pesquisa desenvolvida para o Mestrado em Direito Processual da Universidade Federal do Espírito Santo ([autor], 2017).
} 
Para se alcançar o objetivo da pesquisa e compreender a adoção naquelas três formas, entendemos necessário investigar além do discurso plasmado nos "textos sagrados" do Direito (leis, doutrina e jurisprudência). O método jurídico tradicional de exame desses textos não se revelou suficiente para a compreensão da homoparentalidade adotiva, uma vez que, marcadamente nessa área, o funcionamento do Direito é condicionado por outros fatores para além das normas legais. Por exemplo, não obstante o Estatuto da Criança e do Adolescente (ECA) não listar a orientação sexual como um impedimento à adoção, as regras sociais (GIDDENS, 2003) podem servir como obstáculo. Desse modo, limitando-nos àqueles textos, limitaríamos também a compreensão dos fatores que, embora deles não constem, são determinantes para os resultados existentes.

A fim de suprimir o vazio que os métodos jurídicos clássicos deixariam, foi utilizada a Antropologia, a qual, nas palavras de Oliveira et al. (2012, p. 12), "procura esmiuçar os sentidos das práticas e dos saberes locais, indagando se a singularidade da situação etnográfica pesquisada tem algo a nos dizer sobre o universal". Nesse passo, foram utilizados os métodos da etnografia, entendida como observação participante (ROCHA; ECKERT, 2008) e uma descrição densa dos elementos observados (GEERTZ, 2008), e da história de vida junto a 21 interlocutores (dentre pais, filhos, opositores à adoção homoafetiva, prospectivos pais, pessoas que nunca quiseram adotar, militantes), contatados por meio de rede de conhecidos (snowball sampling), entre outubro de 2015 e julho de 2016. Neste artigo, porém, serão referenciadas somente as famílias formadas por homossexuais $^{7}$ que adotaram, pretendem ou pretenderam adotar. Esses métodos visaram à compreensão de quais estratégias esse pais se valeram para adotar, por que as preferiram em relação a outras, em que medida o Estado interferiu nisso, e como se desenvolve a rotina em suas casas. Assim, além do ordenamento jurídico, entendemos necessário averiguar fatores sociais que afetam o modo como essas famílias organizam suas vidas.

A pesquisa de campo revelou que essas famílias procuram reproduzir os diversos aspectos que conformam a noção de família heteronormativa, especialmente o alto investimento no cuidado com os filhos (BADINTER, 1985; DONZELOT, 1986). Demais disso,

\footnotetext{
${ }^{7}$ Na pesquisa que resultou na dissertação, foi também ouvida uma transexual.
} 
o trabalho de campo demonstrou que, não obstante a possibilidade jurídica de os homossexuais adotarem (individualmente desde a edição do ECA, e em conjunto desde 2011), a adoção perante o Judiciário é mediada por valores e crenças dos agentes públicos relativos à família e à sexualidade. Essa interferência faz com que, por vezes, as adoções não sejam formalizadas ou levadas adiante.

Após esta introdução do tema, o artigo apresentará de que maneira, segundo a perspectiva dos sujeitos da pesquisa, as provisões legais afetam a realização da adoção perante o Judiciário (seção 2), como o padrão heterossexual ainda confere a tônica das adoções, servindo como um facilitador (seção 3), e como a agência dos técnicos, juízes e advogados determina a forma da adoção (seção 4). Em seguida, serão discutidos aspectos relacionados ao cotidiano dessas famílias e o desejo de sua formação (seção 5) em frente aos pânicos morais (MISKOLCl apud COITINHO, 2014) que suscitam. Por fim, apresentamos reflexões gerais dos dados colhidos em campo em face do Direito.

\section{A ADOÇÃO HOMOAFETIVA EM FACE DAS POSSIBILIDADES DA LEI E DA REALIDADE}

No Brasil, nunca houve proibição legal expressa à adoção por homossexuais. A primeira lei a tratar da adoção foi o Código Civil de 1916 (CC/16), alterado, mais tarde pela Lei 3.133/1957. Em seguida, foram editadas as Leis 4.655/1965 e 6.697/1979. Após a promulgação da Constituição Federal de 1988 (CF), o assunto foi regulado pela Lei 8.069/90, conhecida como o Estatuto da Criança e do Adolescente (ECA), alterada pela Lei 12.010/2009. Nenhuma dessas leis faz referência à orientação sexual, embora se entendesse que a adoção por casais homoafetivos fosse vedada até as decisões do STF na Ação de Descumprimento de Preceito Fundamental (ADPF) 132 e na Ação Direta de Inconstitucionalidade (ADI) 4277.

$\mathrm{O}$ art. 370 , do CC/16, estabelecia que "ninguém pode ser adotado por duas pessoas, salvo se forem marido e mulher", o que impedia, expressamente, a existência de dois pais e duas mães (qualquer fosse a relação entre essas pessoas, tais como irmãos), mas não, ao menos explicitamente, a adoção por apenas uma pessoa que fosse homossexual. O mesmo vigeu sob a égide da Lei 3.133/57. Evidentemente, embora não houvesse proibição legal, 
numa época em que a homossexualidade era considerada uma abominação ${ }^{8}$ e uma doença, o homossexualismo ${ }^{9}$, difícil imaginar que algum homossexual pleiteasse a adoção publicamente, ou mesmo que o dispositivo tivesse essa parcela da população como destinatária. Assim, não se pode extrair daquela regra um impedimento à adoção por homossexuais; no máximo, o impedimento à adoção por casais homossexuais. A proibição estava no contexto.

$\mathrm{O}$ art. 2으, da Lei 4.655/1965, fixava que somente poderiam solicitar a "legitimação adotiva" os casais cujo matrimônio tivesse mais de 5 anos e dos quais pelo menos um dos cônjuges tenha mais de 30 anos de idade, sem filhos legítimos, legitimados ou naturais reconhecidos. No mesmo sentido, a Lei 6.697/1979 (Código de Menores) que, ao referir-se aos adotantes, vinculava-os ao casamento presente ou passado (admitia-se a adoção em casos de desquite e viuvez). Assim, a proibição era inerente às possibilidades dos homossexuais, que, uma vez não podendo casar, não poderiam adotar. Além disso, a homossexualidade continuava no rol das doenças, de maneira que seria difícil alguém requerê-lo perante o Estado declarando-se homossexual.

No final da década de 1980, Otávio e José, pelo que se extrai do relato do primeiro (um dos entrevistados), desconheciam essas regras, uma vez que cogitaram adotar um menino que assistia à sua apresentação artística num "orfanato" - de cujo nome, olhos, rosto Otávio se lembra até hoje, como afirmou, sorrindo, em mais de uma oportunidade. Eles não necessitavam conhecer a lei para extraírem das circunstâncias que não Ihes seria possível levar adiante aquele desejo. "Se já é difícil para uma pessoa normal adotar, imagina para a gente, naquela época", contou Otávio.

A julgar pela resignação com que reagiram, certamente, também não estavam cientes de que, à época, "grupos homossexuais, liderados pelo Grupo Triângulo Rosa, do Rio de Janeiro, mobilizaram forças para assegurar, na Constituição de 1988, a expressa igualdade entre homossexuais e heterossexuais" (MELLO, 2005, p. 52). Forças essas que, dentre muitos outros fatores, levariam às novas possibilidades de adoção advindas com o

\footnotetext{
8 “Não te deitarás com um homem como se fosse mulher. É uma abominação" (Levítico 18:22).

${ }^{9}$ De acordo com Dias (2014, p. 64): “Na Idade Média, em face da influência das concepções religiosas, a Medicina considerava o 'homossexualismo' uma doença, enfermidade que acarretava diminuição das faculdades mentais. Um mal contagioso decorrente de um defeito genético. A ideia da sexualidade com doença existe desde o início da denominada sientia sexualis".
} 
ECA, editado sob uma Constituição que, pela primeira vez, não condicionava a família ao casamento heterossexual, embora tenha resultado silente quanto à orientação sexual. Segundo as novas regras adotivas, conforme a redação de 1990, passaram a poder adotar quaisquer pessoas maiores de 21 anos (em 2009, com a Lei 12.010, a idade passou a ser 18 anos), independentemente do estado civil. Nenhuma referência foi feita à orientação sexual, de modo que o entendimento vigente era de que, à falta de proibição expressa, homossexuais solteiros poderiam adotar, ainda que essa possibilidade fosse vista como um "mal menor" (UZIEL, 2012). Nesse sentido, afirmava o jurista Leite que a adoção por homossexual "só [é] justificável pela irresistível intenção do legislador em favorecer ao máximo o aumento das adoções no Brasil, com vistas a contornar o problema do menor abandonado" (LEITE apud SALAZAR JR, 2006, p. 133)

A partir de meados dos anos 1990 em diante, a questão da homoparentalidade ganhou ainda mais destaque nos meios jurídicos. Parte das razões para esse fenômeno se deu pelo pleito dos grupos LGBT e da apresentação do Projeto de Lei 1.151/95 (MELLO, 2005), que visava à regulamentação das parcerias civis, isto é, os direitos dos casais formados por pessoas do mesmo sexo. Nas discussões desse Projeto, a adoção - que não era objeto de regulamentação - foi mencionada como incompatível com a homossexualidade por parte do psiquiatra chamado a se manifestar sobre as parcerias. Segundo Mello (2005, p. 78):

[...] a partir do entendimento equivocado de que o projeto estaria a facultar a possibilidade de adoção de crianças por casais homossexuais, a maior parte da exposição de Cláudio Pérsio [psiquiatra e psicanalista ouvido] esteve centrada na tentativa de demonstração da inconveniência dessa possibilidade. Em suas palavras: "Para tentar demonstrar a inadequação do capítulo da adoção [sic!] no corpo dessa lei, usarei argumentos médicos, médico-psiquiátricos e psicanalíticos."

Em sua exposição, o psicanalista defende, como "inquestionável", a necessidade da presença de um pai-homem e de uma mãe-mulher, que se complementem em termos sexuais e de gênero, no processo de socialização e de desenvolvimento "psicobiológico" das crianças. Considera que os homossexuais envolvidos em vínculos afetivo-sexuais estáveis - potencialmente contratantes de união civil, portanto - não deveriam ser autorizados a desempenhar as funções parentais, uma vez que, ao romperem com as expectativas sociais relativas aos papéis sexuais e de gênero, influenciariam negativamente seus filhos quando da "definição" de sua orientação sexual. 
Discursos dessa ordem sugerem que essas opiniões científicas são o motivo pelo qual as duas adoções participantes da pesquisa de campo que ocorreram na década de 1990 se passaram extraoficialmente. Segundo o advertia Foucault (apud BERT, 2013 ${ }^{10}$ ), o conhecimento científico fala antes sobre o contexto e as condições em que produzido do que sobre o objeto do conhecimento em si mesmo, de maneira que esse parecer não refletiam apenas a opinião de um especialista, mas de toda uma conjuntura de que essas famílias participavam. Por isso, Luciano nunca formalizou a adoção de Ronaldo - que, em 1996, pediu para que fosse levado embora "daquele lugar ruim", com o que sua família biológica consentiu. Ao "procurar se informar" com conhecidos formados em Direito, Luciano se sentiu desestimulado, porque não concederiam uma adoção para ele, "bicha". No caso de Cristina, ela não listou a lei e seus operadores como uma dificuldade na adoção à brasileira de Cristiano, em 1998. Quando sua amiga, que o adotaria, adoeceu, ela "o pegou", registrando-o como se tivesse nascido em casa - ressaltando que ficou de resguardo, "andando assim" (curvou-se um pouco e abriu as pernas, simulando andar, mesmo que sentada). Em que pese ela não tenha dito que o registro sem a intermediação do Estado-juiz se deu em razão de sua homossexualidade, é de se cogitar que se o Direito fosse mais receptivo, ela o teria feito.

Por outro lado, não se pode olvidar de que a prática da adoção à brasileira era arraigada à cultura brasileira, como se se tratasse de matéria em que o Estado não devesse interferir, como a história de André sugere. Em meados dos anos de 1980, suas mães rogavam a Nossa Senhora para que Ihes desse um filho. Um dia, elas foram avisadas de uma moça que deu à luz um menino, que não queria criar. A "mãe mais velha", como André se referia, registrou-o como se fosse seu filho biológico, não contatando o Estado.

A mudança no cenário jurídico advinda com o reconhecimento jurídico das uniões homoafetivas pelo STF, em 2011, e dessas adoções, em 2015 (Recurso Extraordinário 846.102), não implicou a certeza dos homossexuais de que teriam sua adoção concedida. Em 2016, Marie e Clara ressaltaram que um dos maiores impedimentos para que não

\footnotetext{
10 "Os discursos são práticas sujeitas a regras particulares, entre elas, a regra de estarem sempre ligados a seu contexto de produção. Quais são, muito concretamente, as condições de aparição, de desenvolvimento e de desaparição dos discursos? Por que o conteúdo dos discursos variam em medida tão expressiva de acordo com as épocas?" (BERT, 2013, p. 181.)
} 
tivessem iniciado o processo de adoção que planejavam era a ausência de previsão legal expressa. Sendo advogada, Marie conhecia as decisões do Tribunal e seu efeito vinculante. No entanto, ela ponderou a vulnerabilidade de se conceder direitos por via do Judiciário: "se mudarem os Ministros, a decisão pode mudar; é mais difícil revogar uma lei" ${ }^{11}$. Sua fala ilustra a sensação de que, apesar dos esforços da doutrina, do Judiciário, da Defensoria e do Ministério Público, os homossexuais ainda se veem desamparados, em razão da falta de lei, fruto do trabalho do Legislativo.

O tratamento jurídico da adoção, que variou entre o silêncio absoluto e a possibilidade concedida pela via judicial, impacta concretamente no desejo e na forma como os homossexuais adotam. Quando a família foi trazida para o campo do Direito por meio do biopoder (FOUCAULT, 1999), o Estado passou a ditar os pais e as mães aceitáveis. Quando homossexuais não são referidos como tais, eles precisam encontrar alternativas para exercer a parentalidade - se não dela desistirem, como foi o caso de Otávio e José. A desistência ou os caminhos vicinais que encontram derivam das restrições impostas pelo Direito.

O Direito (tanto a ciência quanto as normas), enquanto linguagem (MOUSSALLEM, 2001), absorve e repercute as múltiplos vozes de seu tempo, indicando quais são "as tendências sociais estáveis" (BAKHTIN, 2006, p. 149) de um tempo e de um lugar. Ele gramaticaliza elementos "socialmente pertinentes e constantes" (BAKHTIN, 2006, p. 149), refletindo e influenciando simultaneamente a realidade. Assim, quando o vocábulo "homoafetivo" ingressa no campo jurídico, ele facilita que as adoções se passem sob a tutela do Direito. Mas quando esse termo ou seus afins não constam de leis (em sentido estrito), sua ausência demonstra que o campo jurídico e a sociedade ainda são hesitantes sobre o tema, e, por isso, os homossexuais ainda têm motivos para desconfiar do Estado. Assim, as regras jurídicas, como espécie de regras sociais fortemente sancionadoras, limitam as ações dos atores sociais, ao se incrustarem em sua consciência prática por meio do monitoramento que exercem sobre os aspectos dos contextos em que se movem (GIDDENS, 2003). Desse modo, a maneira como o Direito trata a parentalidade dos homossexuais influi concreta e diretamente na maneira como eles buscam adotar.

\footnotetext{
${ }^{11}$ As falas dos sujeitos da pesquisa são transcrições aproximadas, visto que as conversas não foram gravadas.
} 


\section{A HETERONORMATIVIDADE COMO “ABRIDORA” DE PORTAS}

O silêncio legal não aparece sozinho como um elemento a ser ponderado quando da busca pela adoção. Desde o início da vigência do ECA, qualquer pessoa pode adotar individualmente, independentemente da orientação sexual. No entanto, comparecer perante o Judiciário para pleitear a adoção de uma criança, assumindo publicamente a homossexualidade, foi, por muito tempo, - e ainda é - uma barreira.

Durante as conversas, aqueles que referiram a si mesmos como "bicha/viado" ou demarcaram uma divisão entre si e os "normais/heterossexuais" viram-se mais desestimulados a buscar o Judiciário. Embora juridicamente a visibilidade social da orientação sexual não deva pesar sobre a escolha entre adotar formal ou informalmente ou deixar de adotar, ela influencia, na prática. Isso demonstra que a adoção por homossexuais também ocorre, na observação de Bourdieu (2012, p. 77), "segundo a lei universal de ajustamento das esperanças às oportunidades, das aspirações às possibilidades", que desencoraja a própria inclinação de realizar atos, "mesmo sem estes Ihes serem recusados".

O caso de Luciano, citado acima, exemplifica bem a influência da heteronormatividade. Ao referir a si próprio como "bicha", ele entende que a visibilidade de sua homossexualidade o afastava das adoções por homossexuais que a lei objetivava tutelar. Sua interpretação das circunstâncias parece acertada quando se verifica como a doutrina tratava o tema na época. O jurista Czajkowski (apud SALAZAR JR, 2006, o. 133), em publicação datada de $1995^{12}$, entendia que um homossexual solteiro poderia adotar, desde que mantivesse "sua vida sexual, íntima, apartada, separada do ambiente doméstico que o adotado irá frequentar". Aos homossexuais, então, era dado adotar somente se fossem discretos, somente se sua homossexualidade fosse escondível.

Aproveitando-se disso, Maria Cláudia, à época solteira, procurou o Judiciário no início dos anos 2000 para adotar uma menina. Por medo de lhe ser indeferido o pedido de habilitação, ela omitiu ser homossexual. Segundo suas palavras, não lhe perguntaram e ela não disse. Embora as mães de Luara não tenham participado da pesquisa, é possível

\footnotetext{
${ }^{12}$ De acordo com a bibliografia da dissertação de SALAZAR JR (2006), o entendimento de Rainer Czajkowski foi exposto na obra "Reflexos jurídicos das uniões homossexuais. Jurisprudência Brasileira 176: 95-107".
} 
cogitar que esse fator também tenha contribuído para que uma de suas mães a tenha registrado pela via estatal nos anos de 1980 , quando a encontrou ainda suja do parto, num canto da escola onde trabalhava. A ausência de questionamentos acerca da vida sexual de Maria Cláudia e a possibilidade de procurar a polícia e o Judiciário no caso da mãe registral de Luara confirmam a dedução de Uziel (2012) de que, nos processos judiciais, ocorre uma naturalização tal da maternidade que não se discute nos autos a orientação sexual de mulheres solteiras ${ }^{13}$, ao contrário do que acontece com os homens:

Na pesquisa realizada entre 1999 e 2001 na então 1ạ Vara da Infância e da Juventude da Comarca da capital do Rio de Janeiro, duas questões pareceram importantes: a suspeita que o pedido de adoção por um homem sozinho causava na equipe técnica e nos operadores do Direito, e a feminilização desses homens à medida que iam traçando seu percurso pelos órgãos responsáveis pela elaboração do parecer que orientaria a sentença do juiz. Nesta mesma pesquisa, em função da dificuldade em localizar processos cujas requerentes fossem mulheres lésbicas, suspeitei que a naturalidade com que se concebe a maternidade inibisse, na equipe técnica e no Ministério Público, a dúvida sobre a orientação sexual das pretendentes a mãe, o que não acontecia em relação aos homens que buscavam a paternidade sozinhos, portanto, fora da conjugalidade.

O reconhecimento jurídico das uniões homoafetivas, no entanto, mudou esse cenário. Em 2013, Bento e João, juntos há quase 30 anos, tiveram a adoção conjunta de Vitor deferida. Também por volta desse ano, Cristina habilitou-se para a adoção ${ }^{14}$ com sua então companheira. A possibilidade de irem como casais, em vez de individualmente, comprova a mudança na sociedade e no ordenamento jurídico.

Por outro lado, o fato de se tratar de casais estáveis e afinados com padrões heterossexuais reforça a importância da heteronormatividade como padrão a ser repetido também por homossexuais. Logo no início de nossas conversas, Bento e Cristina enfatizaram que a maioria de seus amigos é heterossexual e que não se veem, em essência, como diferentes dos heterossexuais. Tais caracterísitcas que se autoatribuíram, associadas ao fato de que viviam relacionamentos duradouros e estáveis ao tempo da adoção, aproximam-nos do padrão de sexualidade mais valorizado na sociedade. Sendo

\footnotetext{
${ }^{13}$ A mãe de Luara era solteira oficialmente, mas não na prática.

${ }^{14}$ Foi a quarta adoção de Cristina. Em 1998, ela adotou Cristiano à brasileira. No início dos anos 2000, ela "pegou" Pablo para criar, mas ainda não consta em seu registro. Ao final da primeira década dos anos 2000, ela começou a criar a neta de sua ex-companheira, que ainda tem em seu registro sua mãe biológica, com a qual tem contato frequente.
} 
assim, tornaram-se elegíveis para a legitimação estatal (BUTLER, 2003). Aproximar-se do padrão heterossexual "ótimo" é um aliado ao reconhecimento do Estado quando do novo tratamento jurídico, como explica Coitinho Filho (2015, p. 175-176) sobre a homoafetividade:

A antropóloga Gayle RUBIN (s/d) indicou que o mundo ocidental traçou limites que funcionam como um sistema ideológico - da mesma forma que o racismo, o etnocentrismo e o chauvinismo religioso - do que considera, em termos de expressão e práticas sexuais, um "bom" e um "mau" sexo.

Ao hierarquizar condutas sexuais o ocidente tornou algumas aceitas, outras toleradas e outras desprezíveis. Nesta lógica, atos sexuais passaram a ser avaliados de acordo com um sistema piramidal de valores sexuais. Segundo a autora, heterossexuais maritais e reprodutivos estariam sozinhos no topo da pirâmide erótica, seguidos de heterossexuais monogâmicos não casados e que não reproduzem. Casais lésbicos e gays estariam no meio desta pirâmide. No final estariam "sapatões", os gays promíscuos e, na base, os mais desprezados como os transexuais, travestis, fetichistas, sadomasoquistas, prostitutas etc. (Rubin, s/d).

Assim, tornar o homossexual um "homoafetivo" representaria a alocação deste na fronteira de maior respeitabilidade. Seria uma forma de reduzir um estigma que 0 associa ao comportamento sexual "promíscuo", aproximando-o de um modelo heteronormativo (BUTLER, 2003; MISKOLCl, 2007) conjugal e monogâmico de conduta sexual.

Assim, é possível deduzir que quando Maria Cláudia afirmou que, se fosse adotar novamente, o faria com sua companheira, ela se valia não somente de um novo entendimento jurídico, como também de sua proximidade desse "padrão ótimo". Mas não somente a lei e a posição na hierarquia explicam sua nova postura. Maria Cláudia exaltou a conduta de um agente público judicial que tem atuado na defesa de seus direitos e influenciado o meio, indicando que o outro fator determinante para uma eventual nova adoção seria a confiança nos agentes locais.

\section{AS PESSOAS REAIS VERSUS AS PREVISÕES LEGAIS}

A postura dos agentes públicos com quem os prospectivos pais lidam ou devem lidar mostrou-se determinante sobre a maneira como os homossexuais adotam na Grande Vitória - ES. Essa postura pode ser inferida do contexto, por meio da interpretação da conjuntura em que se inserem, ou mesmo concretamente presenciada, através do contato direto com esses agentes. Suas disposições, com base nos relatos colhidos em campo, são pautadas não apenas pelo Direito, mas refletem seu habitus, visto que reproduzem, 
mesmo sem consciência direta disso, as estruturas sociais vigentes, as quais ainda associam a família ao casal heterossexual (LIN, 1999).

O medo de que os agentes públicos lhes negassem a adoção, utilizando argumentos técnicos para esconder seu preconceito, foi relatado por Marie e Clara. Naturais de outro estado, elas interpretaram a Grande Vitória como um lugar "muito homofóbico". Elas entenderam que a falta de lei que expressamente Ihes garantisse o direito de adoção somada à possível falta de objetividade dos critérios para o deferimento do pleito, num ambiente marcado por preconceitos, indicaria sua falta de sucesso. Por isso, chegaram a cogitar recorrer à adoção à brasileira ${ }^{15}$. Sua extrapolação do ambiente que liam para a postura dos agentes públicos demonstra como, na explicação de Giddens (2003, pp. 139140), "o contexto liga os componentes mais íntimos e detalhados da interação às propriedades mais amplas da institucionalização da vida social".

Embora os participantes da pesquisa que militam no meio tenham afirmado que o Poder Público, à exceção do Legislativo, é hoje receptivo, a suspeita de Marie e Clara não foi totalmente infundada, como ilustra episódio relatado por Bento. Ao final do encontro, ele contou que, após a adoção de Vitor ter sido deferida, um técnico que atuou em seu caso confessou-lhe que, influenciado por convicções religiosas, cogitou dar seu parecer pela negativa. Segundo Bento, o técnico admitiu que todos os aspectos que deveria avaliar eram favoráveis, mas que ele hesitava em opinar positivamente em razão de se tratar de um casal homoafetivo. Não obstante, o técnico opinou pelo deferimento da adoção, que, afinal, se concretizou em favor do casal.

Diversa foi a situação de Paulo e Vinícius. Em 2011, Paulo iniciou o procedimento de adoção. Sua intenção era a de que seu companheiro há sete anos, Vinícius, também fosse pai de Beatriz. Durante o processo, entretanto, um técnico que atuou em seu caso disseIhe que, se houvesse dois pais, o juiz provavelmente indeferiria a habilitação. Assim, somente Paulo prosseguiu como parte e teve a adoção deferida em 2012, mesmo que Vinícius fosse mencionado no processo como seu parceiro.

\footnotetext{
${ }^{15}$ Após o encerramento da pesquisa de campo, elas informaram que deram entrada no procedimento perante a Vara da Infância e da Juventude e tiveram a habilitação deferida.
} 
Sua situação convida a reflexões. Paulo e Vinícius são heteronormativos, pertencem a um dos estratos mais altos da sociedade, e mantêm um relacionamento estável que configurava união estável homoafetiva, já juridicamente reconhecida à época. Eles estavam, portanto, numa posição privilegiada na hierarquia de comportamentos sexuais, tratados anteriormente. Ainda assim, tudo isso não foi suficiente ante as disposições dos agentes concretos com os quais tinham que lidar, o que fez com que apenas um deles se tornasse o pai legal de Beatriz. Além disso, é de se destacar que a adoção iniciada por Paulo ocorreu em período bem próximo a de Cristina e sua ex-companheira e de Bento e João. Todos eles viviam relacionamentos duradouros, o que, em tese os colocaria todos como elegíveis à consagração estatal. No entanto, o fato de Paulo ter optado por uma estratégia diversa da deles (adoção individual $x$ adoção conjunta) mostra o peso da interação com agentes específicos.

Esses dados vão ao encontro dos resultados de outras pesquisas sobre o tema da adoção (FARIAS, MAIA, 2012, pp. 103-105), em que se observou a suscetibilidade dos processos à subjetividade dos agentes. Verifica-se, assim, que convicções pessoais podem se sobrepor aos procedimentos da adoção, fazendo com que nos processos caibam mais agências que a simples pilha de papeis e carimbos.

Essas agências podem se converter em limitações que se apresentam, como apontam Coitinho Filho e Rinaldi (2015), como argumentos técnicos, dentre os quais, o melhor interesse da criança. Assim, as resistências podem vir na forma de laudos de psicólogos, de avaliações de assistentes sociais, de indeferimentos de pedidos ou deferimentos com restrições ao pedido original, de recursos do Ministério Público (MP). Quanto a este último, tem-se um exemplo ${ }^{16}$ apreciado, em 18/08/2015, pela 3a Turma do STJ, no REsp 1.540.814-PR. Segundo o histórico do caso narrado na decisão, foi concedido o registro a homossexual no cadastro para adoção de "criança entre 3 e 5 anos de idade, do sexo masculino, de cor branca até morena clara, saudável, podendo ser filho de portadores de HIV, alcoólatras ou usuários de entorpecentes" (trecho do acórdão). Contra essa concessão, o Parquet recorreu, ao fundamento de que o adotado deveria ter mais de

\footnotetext{
${ }^{16}$ De acordo com pesquisa no site do STJ, cinco decisões tratam de adoção homoafetiva, quais sejam, Recurso Especial 889.852-RS, homologação de sentença estrangeira SE 4.525, Recurso Especial 1.281.093, Recurso Especial 1.217.688, Recurso Especial 1.540.814.
} 
12 anos, a fim de que pudesse manifestar seu consentimento com a adoção. A tese do MP não foi acolhida em nenhuma instância, tendo sido a decisão do juiz mantida pelo Tribunal de Justiça local e pelo STJ. No entanto, ela ilustra um dos muitos desafios que os homossexuais que decidem adotar enfrentam: a convicção pessoal dos agentes públicos a respeito do tema apresentada na forma de peças técnicas. Não é possível calcular quantos são e foram desencorajados por medo de ter de enfrentar essas barreiras.

Apesar do procedimento dar espaço à agência dos seus técnicos, no geral, o Judiciário, o Ministério Público e a Defensoria da Grande Vitória têm se mostrado atentos aos direitos dos homossexuais, como acima mencionado. Assim também, Rafael - que, mesmo tendo dedicado a maior parte do seu relato aos preconceitos que sofre no seu cotidiano, especialmente no seio de sua família - não se mostrou hesitante quando contou sobre seu "sonho" de futuramente adotar quatro filhos com seu noivo. Perguntado se pensava que encontraria dificuldades no procedimento, foi assertivo ao dizer que não. Ele não fundamentou sua impressão nas decisões do STF, na doutrina majoritária ou na jurisprudência, como se poderia esperar de um advogado. O motivo de sua confiança era porque ele havia estagiado em uma Vara da Infância e da Juventude e, por isso, "sabia" que os agentes públicos não baseariam sua eventual negativa na sua homossexualidade. Do mesmo modo, Cristina, quanto à sua habilitação à adoção com sua ex-companheira ${ }^{17}$, queixou-se da vaidade do meio, da demora, da burocracia e da desorganização, mas não do preconceito dos agentes.

Dentre as causas dessa hospitalidade conjuntural nas posturas dos agentes, é possível apontar as decisões do STF na ADPF 132 e na ADI 4277, desde que se lembre que essas decisões, por sua vez, só foram possíveis porque o contexto, antes, havia mudado. Trata-se da interferência recíproca entre Direito e realidade.

\section{FAMÍLIAS “NORMAIS” E MAIORES QUE A LEI}

Entre as décadas de 1970 e 1990, foram realizadas pesquisas nos Estados Unidos da América sobre famílias formadas por pais homossexuais. Comentando sobre essas pesquisas, Elizabeth Roudinesco (apud SALAZAR JR, 2006, pp. 152-153) ressaltou que,

\footnotetext{
${ }^{17}$ Durante o processo, ocorreu a dissolução do relacionamento, e somente Cristina prosseguiu na adoção.
} 
embora tenham explicado pouco sobre a mutação histórica da família, elas "confortaram as angústias dos homossexuais ao mostrarem que eram pais tão comuns quanto os outros". Também na pesquisa de campo, verificou-se o mesmo.

Não obstante as diferenças resultantes de situações de classe, religião, projetos sobre a família e significados da criança no universo doméstico, todos os pais investiam nos cuidados com as crianças, o que fundou o modelo de família atual (DONZELOT, 1986; BADINTER, 1985; PERROT, 2009). Durante suas narrativas, os sujeitos das pesquisas faziam sempre alusão à paz doméstica, às férias, ao almoço em família, à escola, às visitas ao médico. Trata-se de zelos que permearam a construção das memórias dos sujeitos da pesquisa e eram resgatados como parte do "sonho antigo" da parentalidade, que compartilhavam. Assim, Maria Cláudia descreveu, com detalhes, como decorou o quarto de sua filha, colorindo-o em rosa e pintando de branco o berço que havia pertencido à sua afilhada, evocando a memória afetiva daquele objeto como um elemento constituinte de sua família.

Nessas histórias - em que, muitas vezes, o dilema central é a criança engasgada, ou em recuperação, ou com dor de dente -, é fácil esquecer que se trata de homossexuais. Isso leva a crer que a orientação sexual é relacionada a fatos anedóticos da história de cada um e que para esses sujeitos ser mãe ou pai implica, em certa medida, abdicar de si para se devotar ao(s) filho(s). Desse modo, embora a orientação sexual seja determinante no ato da adoção - na medida em que envolve a apresentação de si perante o Estado e a estratégia pela qual a criança que será adotada -, essa característica desaparece nas inúmeras passagens do cotidiano, como ocorreu no encontro com Cristina e seus filhos, em que metade da conversa foi dedicada às histórias sobre travessuras, aventuras de carro e a cavalo, problemas de saúde, distribuição das tarefas domésticas, gostos por filmes e livros.

Não raro, ao compartilhar suas histórias, os sujeitos da pesquisa adjetivaram suas vidas como normais. Ao fazê-lo tomaram como padrão implícito a família heterossexual moderna. Como Pierre Bourdieu (1996) ressalta, pertencer a uma família confere a seus membros o capital simbólico da normalidade. Assim, era importante que o apontassem de inúmeras formas, como nos objetos da casa, nos seus alimentos, nas fotografias. Tais 
imagens de si, proferidas fora da vigilância estatal, refletem as raízes profundas do modelo hegemônico de família. Por isso, a agência dos sujeitos demonstra um esforço em controlar caminhos e estratégias na direção da compleição da heteronormatividade, ainda que, por vezes, estes se vejam fora dela. O exemplo mais significativo da tentativa da reprodução desse modelo se passou na família de André e as mães "mais velha" e "mais nova". Adotado à brasileira por sua mãe mais velha no início dos anos 1980, ele contou que ela chorou quando ele Ihe revelou ser homossexual. Sua reação demonstra que ela pretendia aderir ao padrão heteronormativo, em vez de substituí-lo, o que aparece também como o desejo de outros pais, como aponta Coitinho Filho (2014).

Mas não só a adesão ao padrão heteronormativo e o capital simbólico que dele se segue explica o desejo de constituir família. As experiências pessoais anteriores influenciam nessa construção. Maria Cláudia enfatizou que a adoção é muito comum em sua família. Sua mãe tinha filhos de criação, alguns de seus irmãos adotaram, e ela mesma participou tão ativamente na criação de sobrinhos e afilhados que era um pouco mãe deles também. Por isso, nunca cogitou em realizar fertilização in vitro. A proximidade na criação de sobrinhos e filhos de amigos também foi apontada por Rafael como um dos fatores que o faziam querer adotar. Paulo e Bento também relataram gostarem de crianças anteriormente, mas, tendo priorizado inicialmente compromissos profissionais e a realização de outros projetos, como viagens, adiaram a adoção. O desejo da parentalidade, portanto, apareceu revelado na frase "eu sempre quis ter filhos". Mesmo Cristina, que afirmou que não planejava ser mãe antes de adotar seu filho mais velho, relatou ter sonhado com ele um mês antes de adotá-lo, encontrando uma ligação prévia entre eles. Essas invocações do passado, por vezes, traduzidas no "sempre", apontam para a adoção como algo primordialmente fora do aparato estatal e das leis que a regulam. As biografias são direcionadas, nesse sentido, para aspectos como a eventualidade, o acontecimento, a emoção, enfim, fatos percebidos como fora do escopo da burocracia e seus ritos. É como se o Direito não desse nem pudesse dar conta de tudo o que envolve adotar um filho. 


\section{CONCLUSÃO}

A questão da adoção homoafetiva esbarra no conceito de família enraizado na sociedade de maneira ambivalente. Ao mesmo tempo em que desafiam a diversidade de sexos como fundadora da entidade familiar, as famílias etnografadas reproduzem esse modelo, ao valorizar a organização da vida cotidiana centrando-se nos cuidados com a criança, os quais inauguram a noção de família moderna. Sem embargo dessa reprodução e de o ordenamento jurídico brasileiro atualmente permitir essas adoções, os homossexuais ainda enfrentam empecilhos.

A pesquisa de campo apresentou alguns ângulos sobre esse tema em relação à Grande Vitória, acrescentando ao entendimento de como as relações interpessoais interferem no funcionamento do Direito e como este afeta a vida das pessoas. Apesar de o STF já ter afirmado a juridicidade dessas adoções e de várias decisões ao longo do país as deferirem, os homossexuais ainda encontram problemas e hesitam ao procurar o Judiciário. Eles inferem do contesto que os agentes com os quais têm de lidar possuem habitus próprios, que podem influenciar no processo. Fatores como a heteronormatividade e a existência de decisões anteriores que respaldem seu pleito os fortalecem a buscar a adoção formal, mas não garantem seu sucesso.

A conjugação dos métodos e do olhar da Antropologia ao Direito revelaram questões práticas relacionadas à adoção homoafetiva. A relação entre o Direito e Antropologia expressa neste trabalho consiste, assim como ensina Geertz (1997, p. 253), em um "ir e vir hermenêutico entre os dois campos, olhando primeiro em uma direção, depois na outra, a fim de formular as questões morais, políticas e intelectuais que são importantes para ambos". Mesmo existindo conceitos pré-definidos como no campo jurídico, foi necessário um exame de fatos pequenos com o objetivo de tirar grandes conclusões, a partir da observação etnográfica (GEERTZ, 2003, p. 19-20). Unindo os dois saberes, procuramos contribuir para a compreensão desse fenômeno através de uma nova perspectiva. 


\section{REFERÊNCIAS}

ALBUQUERQUE DE ABREU, Daniel. A semântica da família no jogo democrático brasileiro: uma análise da concepção de entidade familiar proposta pelo Estatuto da Família à luz dos direitos humanos. 2016. 371 f. Dissertação (Mestrado em Direitos Humanos). Universidade Federal De Goiás. 2016.

BADINTER, Elisabeth. Um amor conquistado: o mito do amor materno. Nova Fronteira. Rio de Janeiro, 1985.

BAKHTIN, Mikhail. Marxismo e Filosofia da Linguagem. Hucitec Editora: 12 ed. São Paulo, 2006.

BARANOSKI, Maria Cristina Rauch. A adoção em relações homoafetivas. Editora UEPG: 2 ed. Ponta Grossa, 2016.

BOURDIEU, Pierre. O poder simbólico. Bertrand Brasil: 5 ed. Rio de Janeiro, 2002.

Pierre. Razões Práticas: Sobre a teoria da ação. Campinas, SP: Papirus editora,

11 ed. 2011.

BRASIL. Lei no 12.010, de 3 de agosto de 2009. Disponível em <http://www.planalto.gov.br/ccivil_03/_Ato2007-2010/2009/Lei/L12010.htm\#art2. Acesso em 04.mar.2016.

. Lei no 3.071, de 10 de janeiro de 1916. Disponível em <http://www.planalto.gov.br/ccivil_03/leis/L3071.htm>. Acesso em 04.mar.2016.

Lei no 3.133, de 8 de maio de 1957. Disponível em <http://www.planalto.gov.br/ccivil_03/leis/1950-1969/L3133.htm\#art1>. Acesso em 04.mar.2016.

Lei no 4.655, de 2 de junho de 1965 . Disponível em <http://legis.senado.gov.br/legislacao/ListaPublicacoes.action?id=188100\&tipoDocumento =LEI\&tipoTexto=PUB>. Acesso em 04.mar.2016.

Lei no 6.697, de 10 de outubro de 1979. Disponível em <https://www.planalto.gov.br/ccivil_03/leis/1970-1979/16697.htm>. Acesso em 04.mar.2016.

__. Lei no 8.069, de 13 de julho de 1990. Disponível em <http://www.planalto.gov.br/ccivil_03/leis/L8069.htm>. Acesso em 04.mar.2016.

. Superior Tribunal de Justiça. REsp 1.281.093-SP, 3a Turma, Rel. Min. Nancy Andrighi, julgado em 18.dez.2012, DJe 04/02/2013.

. Superior Tribunal de Justiça. REsp 1.540.814-PR, 3a Turma, Rel. Min. Ricardo Villas Bôas Cueva, julgado em 18.ago.2015. DJe 25/08/2015.

Superior Tribunal de Justiça. REsp 889.852-RS, 4a Turma, Rel. Min. Luis Felipe Salomão, julgado em 27/04/2010. DJe 10/08/2010.

BUTLER, Judith. O parentesco é sempre tido como heterossexual?. Cadernos Pagu, n. 21, p. 219-260, 2003. 
COITINHO FILHO, Ricardo Andrade. "Sobre a possibilidade de se tornar uma 'boa família': afirmações e representações no pleito à adoção movido por gays e lésbicas". In: Novos Debates. Associação Brasileira de Antropologia. v. 1, n. 2, pp. 34-39, jul. 2014.

- O Lugar Do Afeto Na Produção Do "Homoafetivo": Sobre Aproximações Ao Familismo E À Aceitabilidade Moral. Revista Ártemis, v. XIX, p. 168-178, jan-jul 2015.

Ricardo Andrade; RINALDI, Alessandra de Andrade. A "homoafetividade" no cenário adotivo: um debate antropológico. In: Mediações. Londrina, v. 20, n. 1, p. 285306, jan.jun.2015.

CANEVACCI, Massimo. Dialética da Família. Brasiliense. São Paulo. 1981.

DIAS, Maria Berenice. Homoafetividade e os Direitos LGBTI. São Paulo: Revista dos Tribunais: 6 ed. 2014.

DONZELOT, Jacques. A polícia das famílias. Graal: 2 ed. Rio de Janeiro, 1986.

FARIAS, Cyntia Mirella da Costa. A adoção por casais homoafetivos como concretização do direito ao melhor interesse das crianças e adolescentes. Dissertação (mestrado) Universidade de Fortaleza, 2012.

FARIAS, Mariana de Oliveira; MAIA; Ana Cláudia Bortolozzi. Adoção por homossexuais: a família homoparental sob o olhar da psicologia jurídica. Juruá Editora. Curitiba, 2012.

FONSECA, Cláudia. Caminhos da adoção. São Paulo: Cortez editora. 1995.

FOUCAULT, Michel. Em defesa da sociedade: curso no Collège de France (1975-1976). Martins Fontes. São Paulo, 1999.

GEERTZ, Clifford. A interpretação das culturas. Rio de Janeiro: LTC. 2008.

GIDDENS, Anthony. A constituição da sociedade. São Paulo: Martins Fontes, 2003.

LIN, Timothy. Social norms and judicial decisionmaking: examining the role of narratives in same-sex adoption cases. Columbia Law Review, v. 99, 1999, p. 739-794.

MELLO, Luiz. Novas famílias: conjugalidade homossexual no Brasil contemporâneo. Garamond. Rio de Janeiro, 2005.

[autor], 2017. Dissertação de mestrado. [O trabalho não é citado para não comprometer o anonimato]

MOUSSALLEM, Tárek Moysés. Fontes do direito tributário. São Paulo: Max Limonad. 2001.

OLIVEIRA, Luís Roberto Cardoso de; GROSSI, Miriam Pillar; RIBEIRO, Gustavo Lins. Apresentação. In: Antropologia e direito: temas antropológicos para estudos jurídicos. Brasília / Rio de Janeiro / Blumenau: Associação Brasileira de Antropologia / laced/ Nova Letra, 2012, p. 11-15.

PERROT, Michelle. História da vida privada, 4: Da Revolução Francesa à Primeira Guerra. Companhia das Letras. São Paulo, 2009.

RINALDI, Alessandra de Andrade. Adoção Unilateral e a Homossexualidade em Questão. Seminário Internacional Fazendo Gênero 10 (Anais Eletrônicos), Florianópolis, 2013. 
. Laços desfeitos, vínculos construídos e "socioafetividade": um estudo sobre valores morais e práticas legais no cenário da adoção no Rio de Janeiro. In: IV ENCONTRO NACIONAL DE ANTROPOLOGIA DO DIREITO - ENADIR, GT6 Antropologia, famílias e (i)legalidades. 25 a 28 de agosto 2015. São Paulo.

ROCHA, Ana Luiza Carvalho da; ECKERT, Cornelia. Etnografia: saberes e práticas. In: Ciências humanas: pesquisa e método. Coord.: PINTO, Céli Regina Jardim; GUARZELLI, César Augusto Barcelos. Porto Alegre, RS: Editora da Universidade, 2008. Disponível em <http://seer.ufrgs.br/iluminuras/article/viewFile/9301/5371>. Acesso em 08.mar.2016.

SALAZAR JR., João Roberto. Adoção por casais homoafetivos na Constituição Federal. 2006. 189 f. Dissertação (Mestrado em Direito Constitucional). Pontifícia Universidade Católica de São Paulo. São Paulo, 2006.

STANGE, Paula. 1ㅇ casamento legal homoafetivo acontece nesse sábado. <http://www.gazetaonline.com.br/noticias/cidades/2016/05/1-casamento-legalhomoafetivo-coletivo-de-vitoria-acontece-neste-sabado-1013945389.html>. Acesso em: 25.ago.2017.

UZIEL, Ana Paula. Homossexualidade e adoção. Garamond. Rio de Janeiro, 2007.

UZIEL, Ana Paula. O melhor interesse da criança e o "mal menor": quando os requerentes são gays. Scripta Nova: Revista Electrónica De Geografía Y Ciencias Sociales. Universidad de Barcelona. ISSN: 1138-9788. Depósito Legal: B. 21.741-98. Vol. XVI, núm. 395 (3), 15 de marzo de 2012.

OLIVEIRA, Natane Franciella de; MORAES, Janaina Gomes Garcia; SILVA, Sandro José da. Adoção por homossexuais na Grande Vitória - ES: Uma perspectiva interdisciplinar. RBSD - Revista Brasileira de Sociologia do Direito, v. 5, n. 1, p. 164-184, jan./abr. 2018. 